\title{
Evaluation of antioxidant efficacy of different fractions of Tagetes erecta L. Flowers
}

\author{
Padalia Hemali and Chanda Sumitra* \\ Phytochemical, Pharmacological and Microbiological Laboratory, Department of Biosciences, Saurashtra \\ University - Rajkot, 360 005, Gujarat, India.
}

\begin{abstract}
Oxidative stress is an important pathogenesis of numerous chronic diseases. Free radicals and other reactive oxygen species are recognized as agents involved in the pathogenesis of sicknesses. The main characteristic of an antioxidant is its ability to trap free radical. Plants rich in phenolic compounds are generally reported to show good antioxidant activity. Tagetes erecta L (Marigold) belongs to the family Asteraceae. The flowers are especially employed to cure eye diseases, colds, conjunctivitis, coughs, ulcer, bleeding piles and to purify blood. The extractive efficiency of phenolic compounds from plant material is greatly dependent on the choice of solvent. In this study, six solvents of different polarity viz., hexane, toluene, ethyl acetate, acetone, methanol and water have been used for the extraction of Tagetes erecta L. flower by individual cold percolation method. Phenolic and flavonoid content of extracts were determined using Folinciocalteu assays and aluminium chloride colorimetric method respectively. Antioxidant activity was carried out by DPPH radical scavenging activity assay, superoxide free radical scavenging (SO) assay, ABTS radical cation scavenging activity, ferric reducing antioxidant power (FRAP), Reducing capacity assessment. Maximum extractive yield was in water extract followed by methanol extract. There was a direct correlation between phenolic content and antioxidant activity. Methanolic extract had maximum phenolic content and maximum FRAP and SO activity. ABTS and DPPH did not show positive correlation with total phenol content in ethyl acetate extract. Ethyl acetate extract had maximum flavonoid content. T. erecta flowers can be used as a natural source of antioxidants to combat the oxidative stress related disorders.
\end{abstract}

Key word: Tagetes erecta, Influence of solvent, Antioxidant activity, positive correlation

\section{Introduction}

Nature is the best combinational chemist and has cure for all diseases and illness of mankind. Medicinal plants are back bone of several indigenous traditional system of medicine. Traditional used medicinal plants are screened for their antimicrobial efficacy (kalayou et al., 2012). The undesirable effect of the modern medicine has diverted the attention of the people toward herbal medicines.

Oxidative stress is an imbalance between reactive oxygen species (ROS) production and the intracellular capacity for removing ROS. Its leading to excessive damage of all bio molecules like DNA, RNA, lipids, proteins micronutrients like carotenoids, vitamins, etc (Lee et al., 2010) The oxidation induced by free radicals can result in cell membrane destruction and membrane protein disintegration and mutation, which can further initiate the development of many diseases, such as cardiovascular disease, cancer, liver injury, and arthritis (Alok et al., 2014)

Medicinal plants produce many substances that are biologically active and working together catalytically and synergistically to increase the activity (Patwardhan and Gautam, 2005). The plants have effective capacity to scavenge free radicals and represent a source of multifunctional properties. Medicinal plants are rich in secondary metabolites that exhibit a remarkable diversity of both chemical structures and biological activities and are promising source of lead compounds for new drugs targeting neurodegenerative diseases (Dastmalchi et al., 2007).

Plants have different phytoochemicals and depending on their type and concentration they will demonstrate different radical scavenging capacities (Dragland et al., 2003). They may exert cell defensive action by more than one biochemical mechanism (Velioglu et al., 1998). Plant antioxidant play a major role to combat against cellular damage and disease, each plant plays a specific role in disease prevention and treatment.

.Synthetic phenols such as butylated hydroxytoluene (BHT), butylated hydroxyanisole (BHA) and propyl gallate are most frequently used as antioxidants. However, the safety of some of these compounds is questioned because they are have many side effects and are also reported to be carcinogenic. Therefore much interest has been focused on natural antioxidants. Natural antioxidants occur in all higher plants and in all parts of the plant like wood, bark, stems, pods, leaves, fruits, roots, flowers and seeds (Kim et al., 1997). It is now well recognized that the antioxidant activity of these plants is mainly due to the presence of phenolic compounds (Knezeric et al., 2012). 
The extraction yield and the antioxidant activity of the extracts from plants highly depend on the solvent polarity, which determines both quality and quantity of the extracted antioxidant compounds (Franco et al., 2008). The properties of extracting solvents considerably affected the total phenolics content and antioxidant capacity in fruits and vegetables (Michiels et al., 2012) Solvent polarity is very important factor higher the polarity, better the extraction of phenolic compounds (Naczk et al., 2006). The polarity of solvent and its types can influence the mechanisms of hydrogen atom transfer (HAT) and single electron transfer (SET), which are critical for measuring antioxidant properties (Perez-Jimenez and Saura-Calixto, 2006). Different solvents systems have been used for extraction of phenol from plants and their efficiency varies. Commonly used solvents for extracting various substances from plant material are petroleum ether, toluene, ethyl acetate, acetone, and water (Kaneria et al., 2011).

Tagetes erecta L. popularly known as marigold, is grown as an ornamental plant. Flowers of this plant are used in garlands for societal and religious purposes in Eastern countries. The flowers are usually thrown away after their spiritual uses. This plant belongs to the family Asteraceae (Compositae). Different parts of $T$. erecta plant including flower is used in folk medicine. The flowers are especially employed to cure eye diseases, colds, conjunctivitis, coughs, ulcer, bleeding piles and to purify blood (Manjunath 1969; Kirtikar et al. 1994; Ghani, 2003). In the present study, the influence of solvents of various polarity on antioxidant potential of $T$. erecta flowers is evaluated employing various in vitro assay systems like DPPH, superoxide free radical scavenging activity, ABTS, FRAP and reducing power.

\section{Materials and methods}

\section{Chemicals}

All the chemicals were obtained from Hi Media Laboratories and Sisco research Laboratories Pvt. Limited, Mumbai, India. Ultra purified water was used for experiment. Solvents hexane(HE), toluene(TE), ethyl acetate(EA), acetone(AC), methanol(ME), and so on were obtained from Merck, India

\section{Plant material}

Fresh flowers of Tagetes erecta were collected from Rajkot, Gujarat, India. Flower was identified by comparison with specimens at Department of Biosciences (SU/Bio/517Thakrar), Saurashtra University, Rajkot, Gujarat, India. The flowers were washed thoroughly with tap water, petals were separated and shade dried. The dried petals were homogenized to fine powder and stored in air tight bottles which were later used for solvent extraction.

\section{Extraction and Fractionation}

The dried powder of the flower petals was extracted individually by the cold percolation method (Parekh and Chanda, 2007). Fractionation of acetone extract of flower was done by solvent-solvent partition method (Tang et al., 2010).

\section{Determination of total phenol and flavonoid content}

The amount of total phenol and flavonoid content of different solvent extracts of T. erecta and its fraction was determined by Folin- ciocalteu's reagent method (Mc Donald et al., 2001) and aluminium chloride colorimetric method (Chang et al., 2002) respectively.

\section{Antioxidants activities}

The antioxidant activity of the different solvent extracts of $T$. erecta flower and its fraction was evaluated by DPPH free radical scavenging activity, superoxide anion radical scavenging activity, ABTS cation free radical scavenging activity, ferric reducing antioxidant power and reducing capacity assessment by the methods described in our earlier work (Kaneria et al., 2012)

\section{Extractive yield}

\section{Results and Discussion}

The extractive yield of $T$. erecta flower using different solvents with increasing polarity is presented in Fig. 1. The extractive yield was maximum in aqueous extract followed by methanol extract. The extraction ability of different solvents from flower for recovering extractable components followed the order: aqueous $>$ methanol $>$ hexane $>$ acetone $>$ ethyl acetate $>$ toluene. Aqueous extract was superior in their ability to extract phytoconstituents from $T$. erecta $(18.11 \%)$. Extraction with toluene offered the least yield $(0.96 \%)$. Methanol and acetone both are polar solvents but methanol had more extractive yield than acetone and non polar solvent hexane had more extractive yield than polar solvent acetone. Both less polar solvents ethyl acetate and toluene had minimum extractive yield. It can be concluded that polar compounds are more than non polar compounds. Significant differences of extractive yield among different solvents might be attributed to the varied polarity of 
the solvents used as well as the availability of different extractable phytoconstituents present in $T$. erecta flowers. Under the same time and temperature conditions, the solvent used and the chemical property of sample are the two most important factors (Dorta et al., 2012). The choice of solvent has a great influence on the extraction yield but it does not imply that the solvent which had maximum yield will show maximum activity under investigation (Anwar et al., 2013). Maximum extractive yield was in aqueous extract but this may be because it could solubilize large number of compounds which may or may not have antioxidant property. Effect of extraction solvent on antimicrobial and antioxidant activity of medicinal plant extracts is reported by other researchers (Kaneria et al., 2012; Kchaou et al., 2013)

\section{Total Phenol content}

Plant phenolic compounds exhibit remarkable antioxidant activity by scavenging dangerous free radicals like super oxide anion, hydrogen peroxide, hydroxyl radical and nitric oxide generated during normal metabolic processes. Phenolic compounds are secondary plant metabolites with diverse beneficial biological activities such as anti-inflammatory, anti allergic, antibacterial, anti atherosclerotic, anti carcinogenic activity, ant mutagenic, antitumor, antiviral effects (Balasundaram et al., 2006).

Folin-Ciocalteu reagent, a mixture of phosphotungstic $\left(\mathrm{H}_{3} \mathrm{PW}_{12} \mathrm{O}_{40}\right)$ and phosphomolybdic $\left(\mathrm{H}_{3} \mathrm{PMo}_{12} \mathrm{O}_{40}\right)$ acids, is reduced to blue oxides of tungsten $\left(\mathrm{W}_{8} \mathrm{O}_{23}\right)$ and molybdene $\left(\mathrm{Mo}_{8} \mathrm{O}_{23}\right)$ during phenol oxidation. This reaction occurs under alkaline condition provided by sodium carbonate. The intensity of blue colour reflects the quantity of phenolic compounds, which can be measured using spectrophotometer (Conforti et al., 2006).

In the present work, the total phenolic content of $T$. erecta extracts and fractions was measured by the Folin-Ciocalteu method which is expressed as gallic acid equivalents (GAE/g extract) in Fig.2. There were significant differences amongst different solvent extracts. Highest polyphenol content was in polar solvent methanol extract (102.34 mg GAE/g) followed by acetone fraction I and II (79 $\mathrm{mg} \mathrm{GAE} / \mathrm{g})$ and acetone extract (75.91 mg GAE/g). Semi polar solvent ethyl acetate and aqueous extracts had $50 \mathrm{mg}$ GAE/g and $49.98 \mathrm{mg}$ $\mathrm{GAE} / \mathrm{g}$ total phenol content respectively. Lowest phenol content was in toluene extract $(6.81 \mathrm{mg} \mathrm{GAE} / \mathrm{g})$. Effect of solvent was clearly envisaged. Both polar solvents methanol and acetone had more Total phenol content than semi polar solvent extracts toluene and ethyl acetate. Even amongst the polar solvents methanol extract had more Total phenol content than acetone and amongst semi polar solvent extracts ethyl acetate had considerable more Total phenol content than toluene. Ghasemzadeh et al. (2011) report maximum phenol content in methanol extract followed by acetone extract which supports the present results that total phenol content is more in polar solvents (Hegazy et al., 2012; Kamaraj et al., 2012; Kaneria et al., 2012). There is a direct correlation between phenolic content and antioxidant activity of medicinal plants as reported by several researchers (Patel et al., 2011; Kaneria and Chanda, 2013). Plants which have more phenolic content showed good antioxidant activity (Kchaou et al., 2013)

\section{Total Flavonoid content}

Flavonoids are a group of polyphenolic components synthesized by plants with known properties which include free radical scavenging, inhibition of hydrolytic and oxidative enzymes, anti-inflammatory action, antiviral, reduce blood-lipid and glucose, chelation of metal ions and to enhance human immunity (Atoui et al., 2005; Uma Maheshwari and Chatterjee, 2008).

The total flavonoids content of $T$. erecta flowers was also measured spectrophotometrically by using the aluminium chloride colorimetric assay. The amounts of Total Flavonoid content of $T$. erecta flower is shown in Fig.3. Semi polar solvent ethyl acetate and polar solvent acetone extracts shows highest flavonoids content 277.68 and $202.68 \mathrm{mg} / \mathrm{g}$ as compared to other organic solvent extracts. Polar solvent methanol showed flavonoids content $104.32 \mathrm{mg} / \mathrm{g}$ followed by acetone fraction I and II. Aqueous and toluene extract showed lower flavonoid content. Significant differences were detected amongst various solvent extracts of $T$. erecta flower.

\section{2, 2-diphenyl-1-picrylhydrazyl (DPPH) radical scavenging activity}

The DPPH assay is a general test used to evaluate the antioxidant capacity of plant extracts. The DPPH radical is commonly used for fast evaluation of the antioxidant property of a given compound (Bozin et al., 2008). The colour change from purple to yellow after reduction can be quantified by decrease of absorbance at wave length $517 \mathrm{~nm}$. It is usually expressed as $\mathrm{IC}_{50}$ value, the amount of antioxidant necessary to decrease the initial concentration of DPPH by $50 \%$. Lower IC 50 value indicates high antioxidant activity (Molyneux, 2004).

The $T$. erecta flower extracts showed moderate capacity to neutralize this radical; solvent extracts of varied polarity exhibited a wide range of antioxidant capacities. $\mathrm{IC}_{50}$ value of $T$. erecta flower extracts ranged from 30 to $153 \mathrm{ug} / \mathrm{ml}$ (Table.1). Strong DPPH radical scavenging activity was found in the ethyl acetate extract and acetone fraction II. The IC 50 values of ethyl acetate extract was $30 \mathrm{ug} / \mathrm{ml}$ and acetone fraction II was 36 
$\mathrm{ug} / \mathrm{ml}$ and their concentration range was 5 to $30 \mathrm{ug} / \mathrm{ml}$ and 10 to $60 \mathrm{ug} / \mathrm{ml}$ respectively (Fig. 4). However these activities were lower than that of the standard ascorbic acid antioxidant activity whose $\mathrm{IC}_{50}$ value was 11.4 $\mathrm{ug} / \mathrm{ml}$ (Table.1). Polar solvent acetone and methanol extracts showed $\mathrm{IC}_{50}$ values $47 \mathrm{ug} / \mathrm{ml}$ and $74 \mathrm{ug} / \mathrm{ml}$ and their concentration range was 10 to $60 \mathrm{ug} / \mathrm{ml}$ and 15 to $90 \mathrm{ug} / \mathrm{ml}$ respectively. The DPPH free radical scavenging activity of aqueous extract was in the concentration range 30 to $180 \mathrm{ug} / \mathrm{ml}$ and it's $\mathrm{IC}_{50}$ value was $153 \mathrm{ug} / \mathrm{ml}$. Lowest activity was shown by toluene extract whose $\mathrm{IC}_{50}$ value was $>1000$. Among all the solvent extracts, ethyl acetate and acetone fraction II showed moderate DPPH scavenging activity as compared to other solvent extracts. The DPPH radical scavenging of $T$. erecta flower might be attributed to its hydrogen donating ability

\section{Superoxide anion radical scavenging activity (SO)}

Superoxide (SO) and hydroxyl radical $(\mathrm{OH})$ are the two most dangerous free radicals constantly produced in living organisms. SO is considered as major biological source of ROS and they are harmful because they may oxidize and reduce other compounds and potentially form more reactive species via secondary reactions (Estevez and Jordan., 2002). Therefore, superoxide scavenging capacity in the human body is very important as the first line of defence against oxidative stress.

Superoxide anion radical scavenging activity of different solvent extracts and its fraction investigated is shown in Fig. 5. All the different solvent extracts showed poor super oxide anion radical scavenging activity. Out of 7 extracts, 5 extracts showed $\mathrm{IC}_{50}$ values more than $1000 \mathrm{ug} / \mathrm{ml}$, while the reaming extracts showed varied level of activity. Gallic acid was used as standard and its $\mathrm{IC}_{50}$ values was $185 \mathrm{ug} / \mathrm{ml}$. Polar solvent methanol extract and FS I showed superoxide anion radical scavenging activity with $\mathrm{IC}_{50}$ values of 216 and 315 $\mathrm{ug} / \mathrm{ml}$ respectively and its concentration range was from 90 to 540 and 90 to $630 \mathrm{ug} / \mathrm{ml}$ respectively (Fig. 5 and Table. 1).

\section{2, 2'-Azino-bis-(3-ethyl) benzothiazoline-6-sulfonic acid (ABTS) radical cation scavenging activity}

ABTS assay is better to assess the antiradical capacity of both hydrophilic and lipophilic antioxidant because it can be used in both organic and aqueous solvent system as compared to other antioxidant assay. ABTS oxidized with PPS (absorption maxima at $734 \mathrm{~nm}$ ) leads to the generation of ABTS free radicals. This method is based on the ability of antioxidants to reduce the ABTS radical cation (Re at al., 1999). In the present work, different solvent extracts and its fraction were evaluated for their ABTS radical cation scavenging activity. Ascorbic acid was used as standard and its $\mathrm{IC}_{50}$ values was $6.5 \mathrm{ug} / \mathrm{ml}$.

Out of 7 extracts investigated, all the extracts showed ABTS radical cation scavenging activity except toluene extracts. $\mathrm{IC}_{50}$ values ranged from 15 to $102 \mathrm{ug} / \mathrm{ml}$ (Fig 6. Table. 1). Ethyl acetate extract and FS II showed good ABTS radical cation scavenging activity with IC 50 values of 15 and $19 \mathrm{ug} / \mathrm{ml}$ and its concentration range was from 6 to 36 and 8 to $48 \mathrm{ug} / \mathrm{ml}$ respectively (Fig.6 A, F). Polar solvents acetone and methanol extracts showed moderate activity and its IC 50 values were 26.4 and $33 \mathrm{ug} / \mathrm{ml}$ and concentration range was from 8 to 48 and 10 to $60 \mathrm{ug} / \mathrm{ml}$ respectively. Aqueous extract, and FS I showed poor ABTS radical cation scavenging activity (Fig.6 D, E). Among all the extracts, ethyl acetate and acetone fraction I showed moderate ABTS scavenging activity as compared to other solvent extracts. Moderate to weak antioxidant activity by ABTS method was shown by some medicinal plant extracts (Simao et al., 2013).

\section{Ferric reducing antioxidant power (FRAP)}

FRAP is considered to be rapid and is of a semi-quantitative assay. In FRAP assay, antioxidant capacity is evaluated based on the ability of the sample extracts to reduce ferric tripyridyltriazine (Fe (III) TPTZ) complexes to ferrous tripyridyltriazine (Fe (III) - TPTZ). This assay is performed using freshly prepared FRAP regent consisting of 2,4,6-tris (1-pyridyl)-5-triazine (pH 3.6). A blue product (ferrous-TPTZ complex) is formed due to the reduction of ferric iron in FRAP regent (Benzie and Strain, 1996). The higher the FRAP value, the higher will be the antioxidant activity of sample extracts. FRAP activity of $T$. erecta flower is shown in Fig. 7.

Highest antioxidant activity by the FRAP assay was obtained for the extract produced with polar solvent methanol $25.09 \mathrm{M} / \mathrm{g}$ followed by acetone extract $14.83 \mathrm{M} / \mathrm{g}$ respectively (Table 1 ). Acetone fraction I and II showed $14.84 \mathrm{M} / \mathrm{g}$ and $15.83 \mathrm{M} / \mathrm{g}$ FRAP activity. Semi polar solvent ethyl acetate and aqueous extract showed $8.55 \mathrm{M} / \mathrm{g}$ and $7.55 \mathrm{M} / \mathrm{g}$ FRAP activity and toluene extract showed least FRAP activity (Fig.7). The results suggest that methanol extract had maximum antioxidant capacity while toluene extract had least. The results also suggest that extracting solvents play an important role in exhibiting the antioxidant properties of medicinal plants. Siddhuraju (2007) reported similar results for Macrotyloma uniflorum seed extract. 


\section{Reducing capacity assessment}

The reducing power of a compound is related to the electron transfer ability and may therefore serve as a significant indicator of its potential antioxidant activity. However the antioxidant activity of plant extracts may be because of various mechanisms like prevention of chain initiation, binding of transition metal ion catalysts, decomposition of peroxides, prevention of continued hydrogen abstraction, reductive capacity and radical scavenging capacity (Yildrim et al., 2001).

In the present work, the electron donating capacity was measured at a concentration range of 20 to 180 ug/ $\mathrm{ml}$ (Fig.8). The reducing power of all the solvent extracts was dose dependent which showed steady increase with increase in the concentration of the extract. In the present work, the ability of different solvent extracts to reduce $\mathrm{Fe}+3$ to $\mathrm{Fe}+2$ was compared with that of ascorbic acid (standard) and the results are presented in Fig. 8 . Methanol extract showed significantly more reducing capacity than the standard. FS II and Acetone extract showed slightly more and FS I, Ethyl acetate and aqueous extracts showed less activity than the standard. Toluene extract showed least, almost negligible reducing capacity.

The reducing properties are generally shown with the presence of reductones, which have the capacity to donate an electron to free radicals and convert them into stable radicals. Further reductones can react directly with peroxides and also with certain precursors and prevent the formation of peroxides (Wang et al. 2008).

\section{Correlation of antioxidant activity with total phenol content}

Their are several reports that their is direct correlation between the total phenol content and antioxidant activity (Choudhary and Swarnkar, 2011; Kaneria et al., 2012; Zulkefli et al., 2013). But this is not always true; sometimes there is no correlation between total phenol content and antioxidant activity (Kaneria and Chanda et al.. 2012; Chanudom et al., 2013), simply because the non phenolic compounds also contribute to antioxidant capacity of a plant extract (Ismail et al., 2004).

There was a direct correlation between total phenol content and antioxidant activity. Total phenol content was maximum in methanol extract and maximum FRAP and SO activity. On the otherhand, the other two antioxidant assay i.e. ABTS and DPPH did not show positive correlation. It is not necessary that total phenol content shows positive correlation with all antioxidant assays. Toluene had low total phenol content and it showed poor antioxidant activity in all assays done. ABTS and DPPH did not show positive correlation with total phenol content in ethyl acetate extract; ethyl acetate extract had lower phenol content and it had higher ABTS and SO activity. Other solvent extracts showed varied levels of correlation. The results again prove that before concluding the antioxidant capacity of a plant extract, there need to be done more than one antioxidant assay and more than one solvent.

\section{Conclusion}

It can be concluded that the extracting solvent affects significantly the total phenol content and the antioxidant activity measured and therefore it is suggested to use more than one extraction system for better assessment of antioxidant activity. The factors responsible for antioxidant capacity of $T$. erecta flowers are phenolics and non phenolics. On the whole, T. erecta flower extracts exhibited good antioxidant activity. $T$. erecta flowers can be used as a natural source of antioxidants for medicinal use.

\section{Acknowledgement} facilities.

The authors thank Prof. S.P. Singh, Head, Department of Biosciences for providing excellent research

\section{References}

[1]. Alok S, Jain SK, Verma A, Kumar M, Mhor A, Sabharwal M. Herbal antioxidant in clinical practise: A review. Asian Pac J Trop Biomed 2014;4(1):78-84.

[2]. Anwar F, Kalsoom U, Sultana B, Mushtaq M, Mehmood T and Arshad HA. Effect of drying method and extraction solvent on the total phenolics and antioxidant activity of cauliflower (Brassica oleracea L.) extract. Int Food Res J 2013;20(2):653-659.

[3]. Atoui AK, Mansouri A, Boskou G, Kefalas P. Tea and herbal infusions: Their antioxidant activity and phenolic profile. Food Chem 2005;89:27-36.

[4]. Balasundram N, Sundram K, Sammar S. Phenolic compound in plants and agri industrial by-products: antioxidant activity, occurrence and potential uses. Food Chem 2006;99(1):191-203.

[5]. Benzie IF and Strain JJ. The ferric reducing ability of plasma (FRAP) as a measure of "antioxidant power": the FRAP assay. Anal Biochem 1996;39:70-76.

[6]. Bozin B, Mimica-Dukic N, Samojlik I, Goran A, Igic R. Phenolics as antioxidants in garlic (Allium sativum L., Alliaceae). Food Chem 2008; 111: 925-929.

[7]. Chang CC, Yang MH, Wen HM, Chern JC. Estimation of total flavonoid content in propolis by two complementary colorimetric methods. J Food Drug Anal 2002;10:178-182

[8]. Chanudom L, Bhoopong P, Khwanchuea R, Tangpong J. Antioxidant and antimicobial activites of aqueous and ethanol crude extracts of 13 Thai traditional plants. Int J Curr Microbiol App Sci 2014;3(1)549-558.

[9]. Choudhary RK and Swarnkar PL. Antioxidant activity of phenolic and flavonoid compounds in some medicinal plants of India. Nat Prod Res 2011;11:1101-1109 
[10]. Conforti F, Statti G, Uzunov D, Menichini F. Comparative chemical composition and antioxidant activities of wild and cultivated Laurus nobilis L. leaves and Foeniculum vulgare subsp. Piperitum (Ucria) coutinho Seeds. Biol Pharm Bull 2006;29(10)2056-2064

[11]. Dastmalchi K, Dorman HJD, VioralaH, Hiltunen R. Plant as potential source for drug development against Alzhemer's disease. Int J Biomed Pharmaceut Sci 2007;1:83-4104.

[12]. Dorta E, Lobo MG, Gonzalez M. Reutilization of mango byprodut: study of the effect of extraction solvent and temperature on their antioxidant properties. J Food Sci 2012;71(1)80-88.

[13]. Dragland S, Senoo H, Wake K, Holte K, Blomhoff R. Several culinary and medicinal herbs are important sources of dietary antioxidants. J Nutri 2003;133:1286-1290.

[14]. Estevez A and Jordan J. Nitric oxide and superoxide, a deadly cocktail. Ann N Y Acad Sci 2002;962: $207-211$.

[15]. Franco D, Sineiro J, Rubilar M, Sánchez M, Jerez M, Pinelo M, Costoya N, Jose M, Nunez N .Polyphenols from plant materials: extraction and antioxidant power. Elect J Env Agri Food Chem 2008;7(8)3210-3216.

[16]. Ghani A (2003) Medicinal plants of Bangladesh: chemical constituents and uses. Dhaka: Asiatic Society of Bangladesh .

[17]. Ghasemzadeh A, Jaafar HZE, Rahmat Effects of solvent type on phenolics and flavonoids content and antioxidant activities in two varieties of young ginger (Zingiber officinale Roscoe) extracts. J Med Plants Res 2011; 5(7)1147-1154.

[18]. Hegazy AE and Ibrahium MI. Antioxidant activities of orange peel extracts. World App Sci J 2012;18(5):684-688.

[19]. Ismail A, Marjan ZM, Foong CW. Total antioxidant activity and phenolic content in selected vegetables. Food Chem 2004;87:581586.

[20]. Kalayou S, Haileselassie M, Gebre-egziabher G, Tiku'e T, Sahle S, Taddele H, Ghezu M. In vitro antimicrobial activity screening of some ethnoveterinary medicinal plants traditionally used against mastitis, wound and gastrointestinal tract complication in Tigray Region, Ethiopia. Asian Pac J Trop Biomed 2012;2(7):516-522.

[21]. Kamaraj C, Rahuman AA, Siva C, Iyappan M, Kirthi AV. Evaluation of antibacterial activity of selected medicinal plant extracts from south India against human pathogens .Asian Pac J Trop Dis 2012;S296-S301.

[22]. Kamatou GPP, van Zyl RL, van Vuuren SF, Viljoen AM. Chemical composition, leaf trichome types and biological activities of the essential oils of four related salvia species indigenous to Southern Africa. J Ess Oil Res 2006;18: 72-79.

[23]. Kaneria M and Chanda S. The effect of sequential fractionation technique on the various efficacies of pomegranate (Punica granatum L.). Food Anal Methods 2013;6:164-175.

[24]. Kaneria M, Bapodara M, Chanda S. Effect of extraction techniques and solvents on antioxidant activity of pomegranate (Punica granatum L.) leaf and stem. Food Anal Method 2012;5:396-404

[25]. Kchaoua W, Abbèsa F, Bleckerb C, Attia H, Besbesa S. Effects of extraction solvents on phenolic contents and antioxidant activities of Tunisian date varieties (Phoenix dactylifera L.). Indus Crop Prod 2013;45:262- 269.

[26]. Kim BJ, Kim JH, Kim HP and Heo MY. Biological screening of 100 plants for cosmetic use (II): antioxidative activity and free radical scavenging activity. Int J Cosmet Sci 1997;19:299-307.

[27]. Kirtikar KR, Basu BD. Indian medicinal plants. Allahabad: Lalit Mohan Basu India 1994;1385-1386-1987.

[28]. Knezevic VS, Blazekovic B, Stefan BM, Babac M. Plant polyphenols as antioxidant influencing the human health. In phytochemical as nutracuticals-global approaches to their role in nutrition and health: Rao V, Ed; InTech Rijeka Croatia 2012;155180 .

[29]. Kumar MSY, Dutta R, Prasad D, Misra K. Subcritical water extraction of antioxidant compound from sea buckthorn (Hippophae rhamnoides) leaves for the comparative evaluation of antioxidant activity. Food Chem 2011;127: 1309-1316.

[30]. Lee HP, Zhu X, Casadesus G, Castellani RJ, Nunimura A, Smith MA, Lee H, Perry G. Antioxidant approaches for the treatment of Alzeimer's disease. Expert Rev Neurother 2012; 10:1201-1208.

[31]. Manjunath BL (1969) The Wealth of India, Raq material. New Delhi:CSIR.

[32]. Mc Donald S, Prenzler PD, Autolovich M, Robards K. Phenolic content and antioxidant activity of olive extracts. Food Chem 2001;73:73-84

[33]. McCune LM and Johns T. Antioxidant activity in medicinal plants associated with the symptoms of diabetes mellitus used by the indigenous peoples of the North American boreal forest. J Ethanophama 2002;82:192-205.

[34]. Michiels JA, Kevers C, Pincemail J, Defraigne JO, Dommes J. Extraction conditions can greatly influence antioxidant capacity assays in plant food matrices. Food Chem 2012;130(4) 986-993.

[35]. Molyneux P. The use of the stable free radical diphenylpicrylhydrazyl (DPPH) for estimating antioxidant activity. Songklanakarin J Sci Technol 2004;26: 211-219.

[36]. Naczk M and Shahidi F. Phenolics in cereals, fruits and vegetables: Occurrence, extraction and analysis. J Pharmaceu Biomed Anal 2006; 41(5)1523-1542.

[37]. Ozgova S, Hermánek J, Gut I. Different antioxidant effects of polyphenols on lipid peroxidation and hydroxyl radicals in the NAPH Feascorbate Fe-microsomal systems. Biochem Pharmacol 2003;66:1127-1137.

[38]. Parekh J and Chanda S. In vitro antibacterial activity of the crude methanol extract of Woodfordia fruticosa kurz. flower (Lythraceae). Braz J Micro 2007;38:204-207.

[39]. Patel DK, Kumar R, Laloo D, Hemalatha S Evaluation of phytochemical and antioxidant activities of the different fractions of Hybanthus enneaspermus (Linn) F. Muell. (Violaceae). Asain Pac J Trop Med 2011; 4(5):391-396.

[40]. Patwardhan B, Gautam M Botanical immunodrugs: scope and opportunities. Drug Dis Today 2005;10(7):495-502.

[41]. Perez-Jimenez J and Saura-Calixto F. Effect of solvent and certain food constituents on different antioxidant capacity assays. Food Res Int 2006; 791-800.

[42]. Re R, Pellegrini N, Proteggentle A, Pannala A, Yang M, Rice-Evans C. Antioxidant activity applying an improved ABTS radical cation decolourisation assay. Free Rad Biol Med 1999;26:1231-1237.

[43]. Robak J and Gryglewski RJ. Flavonoid are scavengers of superoxide anions. Biochem Pharmacoy 1988;37:837-841

[44]. Siddhuraju P and Manian S. The antioxidant activity and free radical-scavenging capacity of dietary phenolic extracts from horse gram (Macrotyloma uniflorum (Lam.) Verdc.) seeds. Food Chem 2007;105:950-958.

[45]. Simao AA, Lage FF, Chagas PMB, Fraguas RM, Freire JM, Marques TR, Correa AD. Antioxidant from medicinal plants used in the treatment of obesity. Euro J Med Plants 2013;3(3):429-442.

[46]. Tang J, Meng X, Liu H, Zhao J, Zhou L, Qiu M, Zhang X, Yu Z and Yang F. Antimicrobial activity of sphingolipids isolated from the stems of Cucumber (Cucumis sativus L.). Molecules 2010;15:9288-9297.

[47]. Umamaheswari M and Chatterjee TK. In vitro antioxidant activities of the fraction of Coccnia grandis L. leaf extract AFR. J Trad comp Alter Med 2008;5;61-73.

[48]. Velioglu YS, Mazza G, Gao L, Oomah BD .Antioxidant activity and total phenolics in selected fruits, vegetables, and grain products. J Agric Food Chem 1998;46:4113-4117. 
[49]. Wang H, Gao XD, Zhou GC, Cai L, Yao WB. In vitro and in vivo antioxidant activity of aqueous extract from Choerospondias axillaris fruit. Food Chem 2008; 106:888-895.

[50]. Yildirim, M. Oktay, Bilaloglu V. The antioxidant activity of the leaves of Cydonia vulgaris. Turk J Med Sci 2001;31:23-27.

[51]. Zulkefli HN, Mohamad J, Abidin NZ. Antioxidant activity of methanol extract of Tinospora crispa and Tabernaemontana corymbosa. Saina Malaysiana 2013;42(6) 697-706.

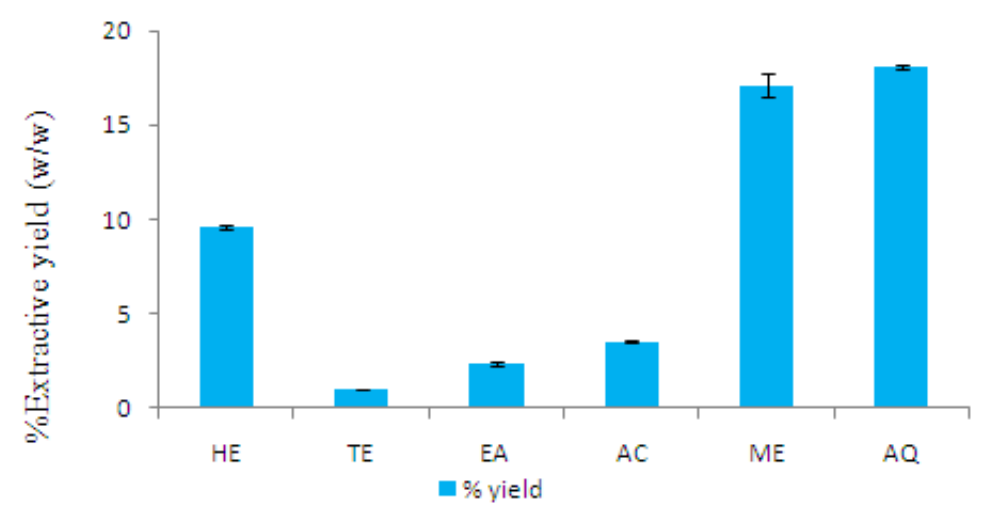

Solvent extracts

Fig. 1: Extractive yield of T. erecta flower in different solvent extracts

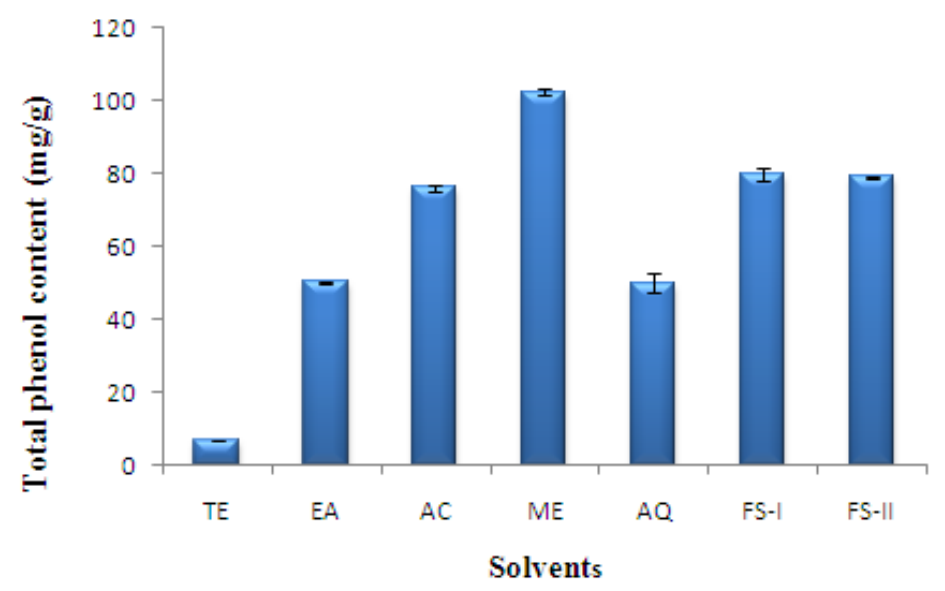

Fig. 2: Total phenol content of different solvent extracts of T. erecta flower

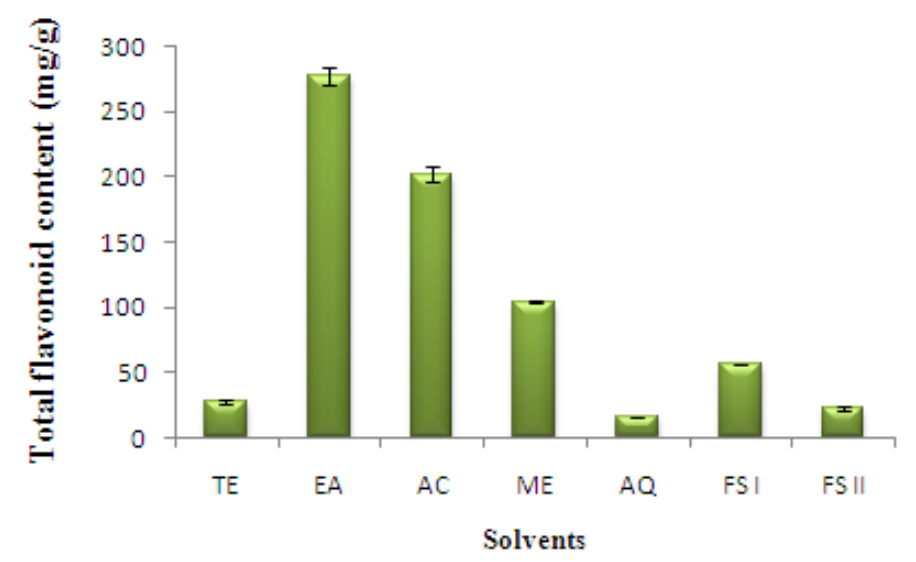

Fig. 3: Total flavonoid content of different solvent extracts of T. erecta flower 

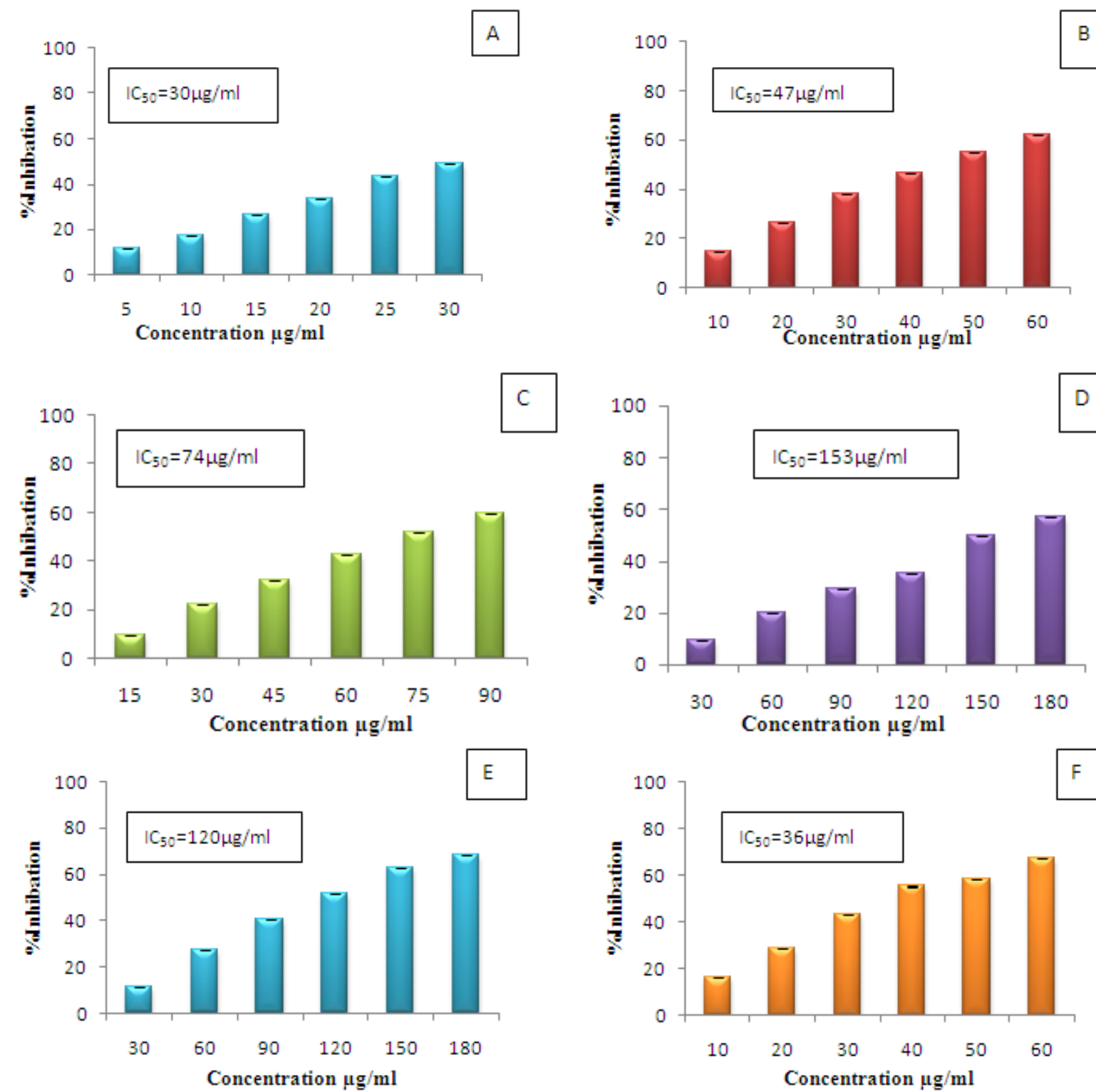

Fig. 4: DPPH free radical scavenging activity of T. erecta flower in different solvent extracts (A) Ethyl acetate (B) Acetone (C) methanol (D)Aqueous (E) Acetone Fraction I (F)Acetone Fraction II

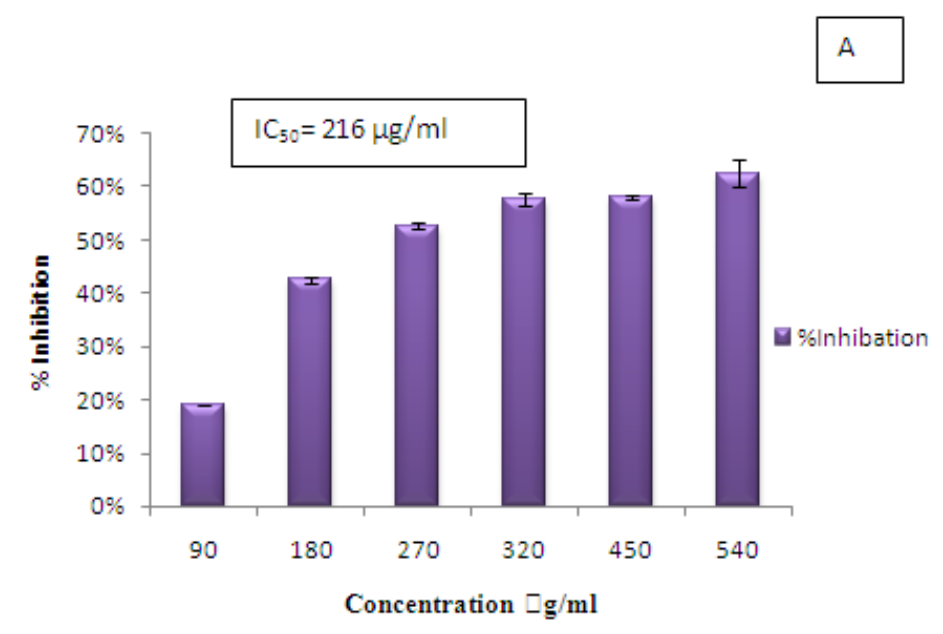




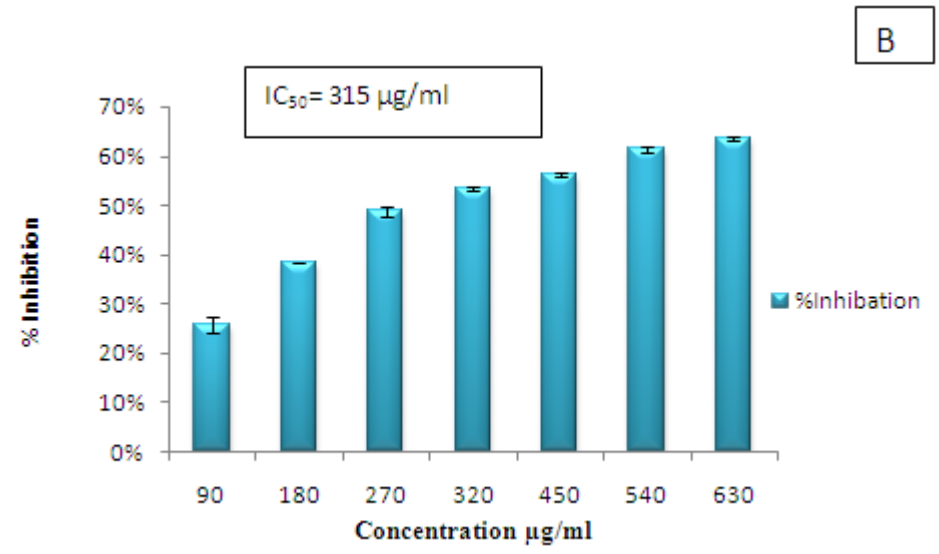

Fig. 5: Super oxide free radical scavenging activity of $T$. erecta flower in different solvent extracts (A) Methanol (B) Acetone Fraction I
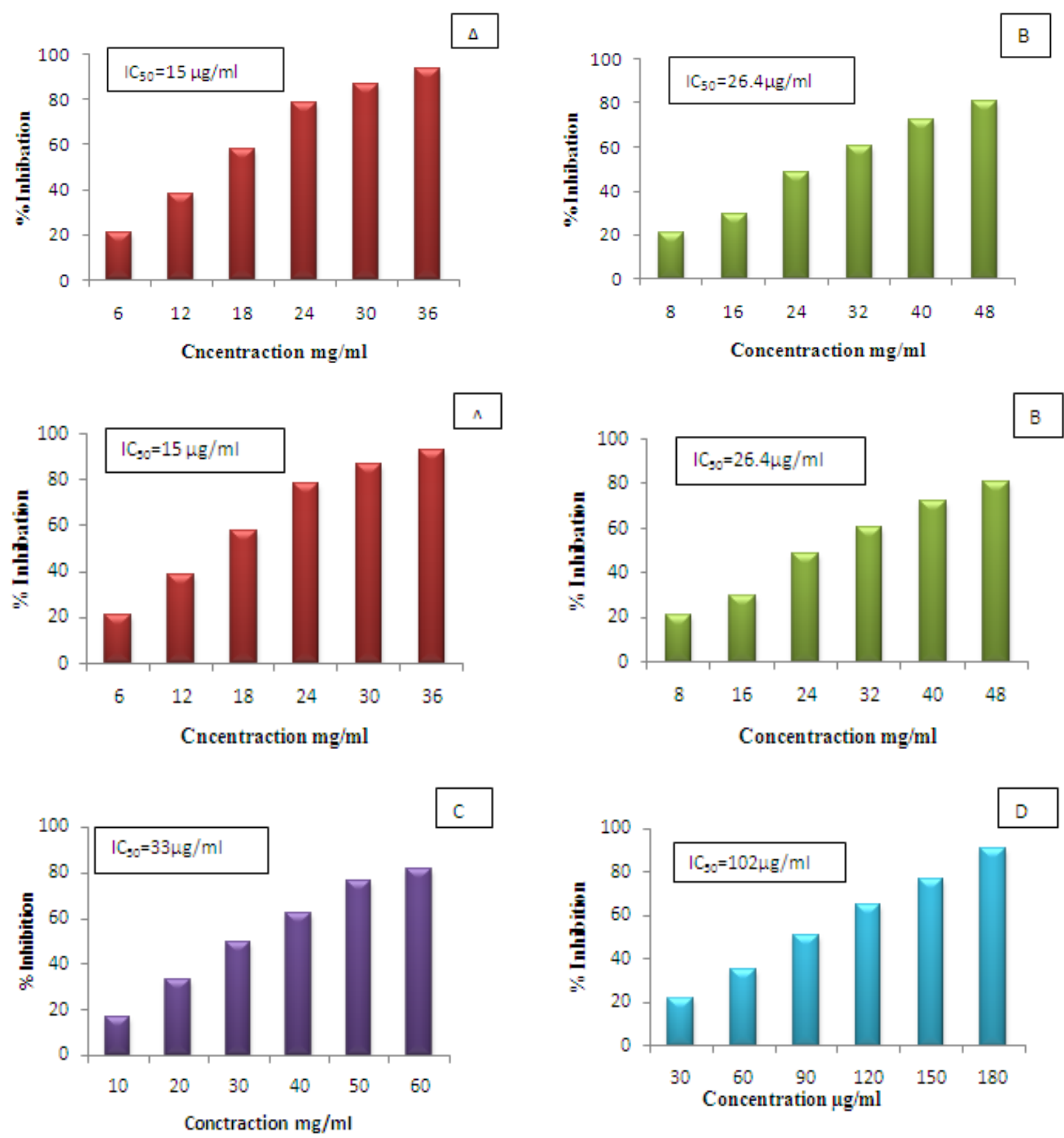

Fig. 6: ABTS radical cation scavenging activity of $T$. erecta flower in different solvent extracts (A) Ethyl acetate (B) Acetone (C) methanol (D)Aqueous (E) Acetone Fraction I (F)Acetone Fraction II 


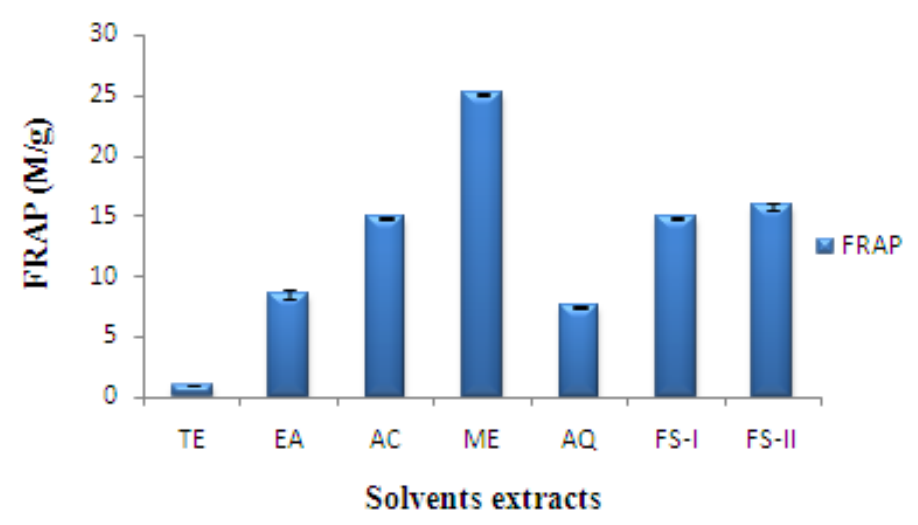

Fig. 7: Ferric reducing antioxidant power (FRAP) of different solvent extracts of T. erecta flower

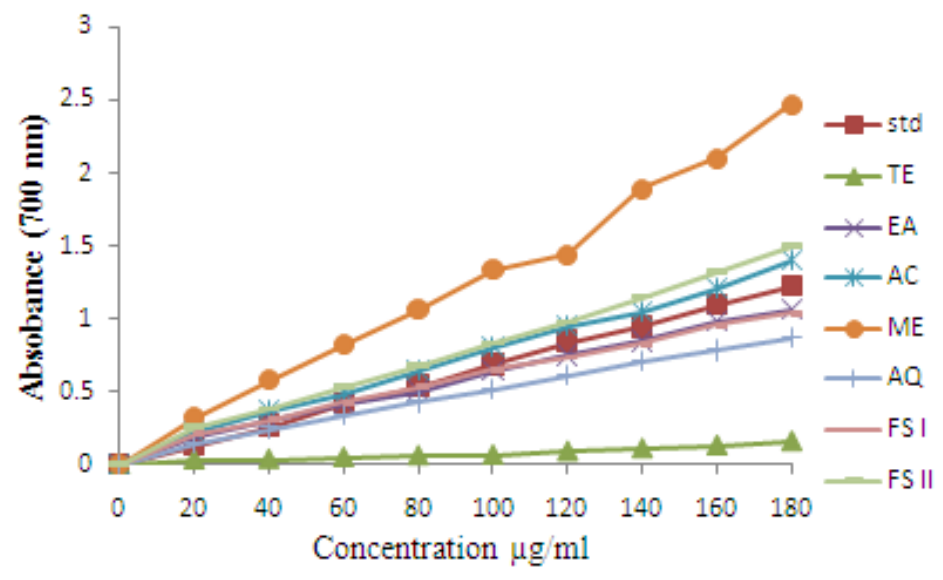

Fig. 8: Reducing capacity assessment of standard ascorbic acid and different solvent extracts of T. erecta flower

Table 1: $\mathrm{IC}_{50}$ values of antioxidant activity of different solvent extracts of $T$. erecta flower

\begin{tabular}{|c|c|c|c|c|c|}
\hline \multirow[t]{2}{*}{ No. } & \multirow[t]{2}{*}{ Solvent } & \multicolumn{3}{|c|}{$\mathrm{IC}_{50}$ Value $(\mu \mathrm{g} / \mathrm{ml})$} & \multirow[b]{2}{*}{$\begin{array}{c}\text { FRAP activity } \\
\mathrm{M} / \mathrm{gm}\end{array}$} \\
\hline & & DPPH activity & SO activity & ABTS activity & \\
\hline 1 & Toluene & $>1000$ & $>1000$ & $>1000$ & 0.944 \\
\hline 2 & Ethyl acetate & 30 & $>1000$ & 15 & 8.55 \\
\hline 3 & Acetone & 47 & $>1000$ & 26.4 & 14.83 \\
\hline 4 & Methanol & 74 & 216 & 33 & 25.09 \\
\hline 5 & Aqueous & 153 & $>1000$ & 102 & 7.55 \\
\hline 6 & Acetone FS I & 120 & 315 & 80 & 14.84 \\
\hline 7 & Acetone FS II & 36 & $>1000$ & 19 & 15.83 \\
\hline 8 & Standard: Gallic acid & & 185 & & \\
\hline 9 & Standard: Ascorbic acid & 11.4 & & 6.5 & \\
\hline
\end{tabular}

DPPH: 2,2-diphenyl 1-picryl-hydrazyl free radical; SO: superoxide anion radical; 2, 2'-Azino-bis-(3-ethyl) benzothiazoline-6-sulfonic acid (ABTS) radical cation scavenging activity; FRAP: Ferric reducing antioxidant power: 